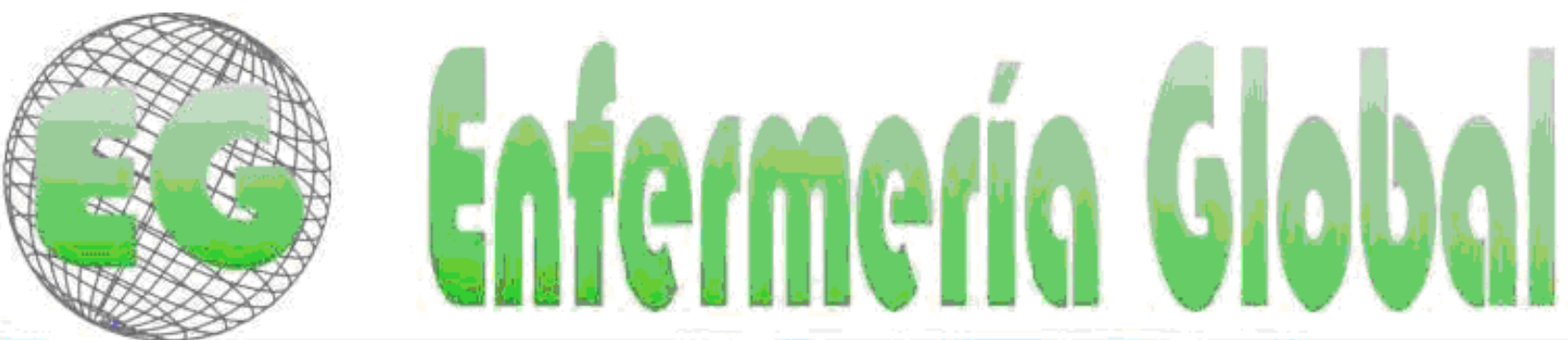

$19 \operatorname{SN} 1695-6144$

$\mathrm{N}^{\circ} 16$

Revista electrónica cuatrimestral de Enfermeria

Junio 2009

www.um.es/eglobal/

REVISIONES - RESEYTAS

\title{
COMPUESTOS FUNCIONALES DE LA LECHE MATERNA
}

FUNCTIONAL COMPOUNDS IN BREAST MILK

*Gómez Gallego, C., "Pérez Conesa, D., "*Bernal Cava, MJ., "Periago Castón, MJ., *Ros Berruezo, G.

*Departamento de Tecnología de los Alimentos, Nutrición y Bromatología. Facultad de Veterinaria. Universidad de Murcia. **Instituto de Nutrición Infantil Hero - Hero España. Murcia

Palabras clave: Alimentación infantil, lactancia, formulas infantiles, compuestos bioactivos.

Keywords: Infant Nutrition, Lactation, Infant Formula, Bioactive Compounds.

\section{RESUMEN}

Los recién nacidos poseen unas necesidades nutritivas especiales debido al incompleto desarrollo de sus sistemas de órganos, que irán abandonando conforme estos sistemas vayan adquiriendo su completa funcionalidad. Al correcto desarrollo del organismo infantil va a contribuir no sólo la correcta nutrición del niño, sino también la acción de muchos compuestos funcionales presentes en la leche materna, entre los que destacan: hormonas, factores de crecimiento, neuropéptidos, agentes antiinflamatorios y agentes inmunomoduladores. Debido a la importancia que tienen estos compuestos en la alimentación infantil hemos realizado una revisión bibliográfica sobre sus diferentes propiedades y su presencia en la leche materna, con el objetivo de poder justificar el empleo de estos productos como ingredientes funcionales en la elaboración de las fórmulas infantiles. En general, dichas fórmulas son deficitarias en estos compuestos bioactivos, por lo que su adición como ingrediente podría incrementar la calidad nutricional de las fórmulas infantiles consiguiendo los mismos efectos positivos que sobre el niño tiene la lactancia materna.

\section{ABSTRACT}

Newborns have special nutritional requirements due to the incomplete development of their organic systems, which will diminish once the organs acquire full functionality. In the complete development of the infant organism, not only the correct nutrition of the child has a great contribution, but also many other functional compounds naturally present in breast milk such as Hormones, growth factors, neuropeptides, anti-inflammatory agents and immunomodulator agents. A thorough review of the scientific literature regarding the properties and occurrence of such functional compounds in breast milk has been carried out due to their importance in the elaboration of infant food. Therefore, the main objective of this work was to give enough scientific evidence for the use of these compounds as functional ingredients in the production of infant formulas. In general, infant formulas lack in these 
bioactive compounds, hence their supplementation with bioactive compounds as ingredients might increase the nutritional value of the infant formulas achieving the same positive effects that human milk has on infants.

\section{INTRODUCCIÓN}

La alimentación durante la infancia está entre los factores más importantes que afectan inmediatamente o a corto plazo al crecimiento, a la composición corporal y a las funciones corporales. Además, la alimentación en este periodo crítico de la vida va a ejercer efectos a largo plazo sobre diferentes procesos fisiológicos y metabólicos, pudiendo jugar un papel clave en la disminución de la incidencia de enfermedades; dada la trascendencia de la alimentación para el óptimo desarrollo físico e intelectual.

Aunque la leche materna, en general, se considera la mejor opción alimenticia, más del $70 \%$ de los niños en Europa Occidental son alimentados con fórmulas desde la decimosegunda semana de vida (1). Según el Codex Alimentarius las fórmulas infantiles se definen como el producto en forma líquida o en polvo utilizado como sustitutivo de la leche materna para satisfacer las necesidades nutricionales normales de los lactantes; o como el producto destinado a lactantes con necesidades nutricionales especiales. Las fórmulas infantiles deberán ser nutricionalmente adecuadas para favorecer el crecimiento normal y el desarrollo de los lactantes cuando se emplean de acuerdo con sus instrucciones de uso. Se caracterizan por cubrir, al menos en cuanto al contenido en macro y micronutrientes, todas las necesidades del lactante durante los primeros cuatro o seis meses de vida, y pueden ser utilizadas junto con otros alimentos hasta la edad de un año ${ }^{(2)}$.

Actualmente se ha conseguido que el contenido de macronutrientes (hidratos de carbono, proteínas y lípidos) y micronutrientes (vitaminas y minerales) de las fórmulas infantiles sea similar al de la leche materna, estando regulado por normas establecidas legalmente ${ }^{(3)}$. Pero la leche materna contiene una gran variedad de compuestos muy importantes en la alimentación del recién nacido, no sólo por su papel nutricional sino también por su carácter funcional. Este tipo de compuestos serían claves en la modulación de rutas metabólicas, de la respuesta inflamatoria y de la respuesta inmune.

Los compuestos bioactivos se definen como constituyentes "extranutricionales" que aparecen de forma normal en pequeñas cantidades en los alimentos, principalmente en productos vegetales, en alimentos con alto contenido lipídico y en la leche ${ }^{(4,5)}$. El interés por la presencia de estas sustancias bioactivas en la leche materna viene reforzado por su ausencia casi general en los preparados para lactantes. Nuevos estudios realizados en las últimas décadas sugieren que la leche materna modula la función y la integridad del tracto gastrointestinal durante el tiempo de lactancia y la infancia. Esta funcionalidad se basa en distintas observaciones en niños alimentados con leche materna:

1. Los niños prematuros alimentados con leche materna parecen ser más resistentes a la enterocolitis necrotizante que los niños nacidos al final de la gestación alimentados con fórmulas infantiles ${ }^{(6)}$

2. Los niños alimentados con leche materna muestran pocos signos de inflamación intestinal durante las infecciones entéricas agudas ${ }^{(7)}$

3. El riesgo de malabsorción intestinal debido a la intolerancia al gluten en niños es menor con la leche materna ${ }^{(8)}$

4. El riesgo de sufrir diabetes tipo I ${ }^{(9)}$, enfermedad de Crohn ${ }^{(10)}$, artritis reumatoide (11) y linfomas ${ }^{(12)}$ en niños mayores parece estar reducido en niños alimentados con leche materna. 
Una gran parte de estas acciones depende de compuestos que forman parte de la fracción nitrogenada no proteica, que en la leche materna supone un $18-30 \%$ del nitrógeno total, mientras que en la leche de vaca (con la que se elaboran las fórmulas infantiles) sólo constituye un $5 \%$ del total ${ }^{(13)}$. El resto de compuestos funcionales de la leche suelen ser oligosacáridos, muchos de los cuales contienen también nitrógeno en su estructura.

\section{OBJETIVOS}

El objetivo del presente trabajo ha sido realizar un estudio bibliográfico para describir la importancia de los compuestos bioactivos en la leche humana y la idoneidad de incorporarlos como nuevos ingredientes en las fórmulas infantiles, de cara a conseguir el mejor desarrollo del lactante.

\section{MATERIAL Y MÉTODOS}

La metodología empleada se basa en el uso de bases de datos electrónicas como MedLine, ScienceDirect, etc., y de la hemeroteca científica de la Universidad de Murcia, tal y como suele ser habitual para este tipo de trabajos.

\section{Componentes biológicamente activos de la leche materna:}

Existen cinco categorías principales para clasificar los agentes biológicamente activos presentes en la leche humana, que podrían modular el crecimiento in vivo, el desarrollo y la función del tracto gastrointestinal ${ }^{(7,13)}$. Estos son:

1. proteínas, péptidos y aminoácidos

2. nucleótidos

3. hormonas

4. factores de crecimiento

5. agentes antiinflamatorios e inmunomoduladores

Estos agentes bioactivos ejercen su acción sobre determinados tejidos diana ${ }^{(7)}$ :

1. el epitelio intestinal, modulando la absorción de nutrientes, la permeabilidad de la mucosa, la proliferación celular, la composición de la microbiota intestinal, la inducción de moléculas de superficie (entre ellas las disacaridasas) y la regulación de la producción de citoquinas

2. el sistema nervioso entérico

3. el sistema inmune de la mucosa

Proteínas, péptidos y aminoácidos:

Dentro de la fracción proteica de la leche destacan por su efecto bioactivo las proteínas del suero, no sólo por la liberación de péptidos con actividad biológica sino por otros efectos generales como la inmunoestimulación directa. Muchas de las actividades biológicas, conocidas o posibles, de determinadas proteínas séricas están relacionadas con funciones del sistema inmune o digestivo ${ }^{(14)}$. Así, las proteínas del suero parecen potenciar la respuesta inmune, tanto humoral como celular ${ }^{(15)}$. La posible acción inmunomoduladora parece estar relacionada también por el aumento en la concentración de glutatión mediada por las proteínas del suero, ya que la presencia de glutatión es necesaria para la actividad y proliferación linfocitaria, particularmente células T e inmunocompetencia ${ }^{(16)}$. Por otro lado, 
leches con altos niveles de inmunoglobulinas, como la leche materna, parecen tener cierto carácter protector y terapéutico frente a la infección por rotavirus en niños ${ }^{(17)}$.

También han aparecido determinados estudios que apuntan a que la leche materna podría tener un efecto tolerogénico, ya que parece disminuir la aloreactividad de los linfocitos T del niño contra los leucocitos de la madre ${ }^{(18)}$. Este efecto es importante ya que las madres pueden aportar linfocitos inmunorreactivos a sus recién nacidos lactantes, lo que va a influir sobre el desarrollo de la inmunocompetencia neonatal. Estas células sobreviven en el estómago y en el intestino del recién nacido, manteniéndose viables en el tracto gastrointestinal superior hasta 1 semana., presentando respuesta a diversos mitógenos, aloantígenos y antígenos convencionales. Estas células aportadas por la madre al lactante permitirían compensar la deficiencia de éste en linfocitos T de memoria ${ }^{(19)}$. Además, en la fracción soluble de las proteínas de la leche también están presentes enzimas que catalizan la destrucción de mediadores de la inflamación y citoquinas antiinflamatorias ${ }^{(7)}$.

\section{Lactoferrina.}

Uno de los componentes más importantes de las proteínas de la leche materna es la lactoferrina, constituyendo alrededor de un 10-15\% de las mismas. Esta proteína favorece la absorción del hierro, tiene actividad antimicrobiana, antiviral y antiinflamatoria; es un factor de crecimiento y proliferación de la mucosa intestinal, y favorece la incorporación de la timidina en el ADN (siendo este último un efecto independiente del hierro) ${ }^{(13)}$. Además, es inmunomodulante y anticarcinogénica ${ }^{(20)}$.

La actividad antimicrobiana de la lactoferrina se ejerce sobre un amplio espectro de patógenos, incluidos hongos, bacterias y virus ${ }^{(21)}$. La función bacteriostática se debe a la capacidad de la lactoferrina para ligar iones $\mathrm{Fe}{ }^{(22)}$, ya que la molécula se encuentra principalmente como apolactoferrina (forma libre de hierro) en las secreciones y tiene la capacidad de secuestrar este metal en los sitios de infección. De esta manera priva de un nutriente esencial a las bacterias inhibiendo su crecimiento ${ }^{(21)}$. La capacidad bactericida de la lactoferrina se atribuye a la interacción directa de la molécula o parte de ella, con las superficies bacterianas, lo que produce un aumento en la permeabilidad de la membrana y la liberación del contenido citoplasmático. Este efecto es similar al producido en hongos y levaduras, pero en este caso es necesario de la molécula entera de lactoferrina. En el caso de virus, la lactoferrina ejerce su acción por competencia, impidiendo su internalización en la célula eucariota $^{(21)}$.

\section{Péptidos bioactivos}

No sólo las proteínas de la leche en su forma activa presentan efectos beneficiosos para el lactante. Muchos péptidos liberados durante la digestión enzimática de proteínas actúan positivamente a muchos niveles. En el lactante, la permeabilidad de la mucosa intestinal es mayor que en el adulto siendo a la vez mayor la resistencia de estos péptidos a la acción proteolítica por lo que pueden atravesar la barrera intestinal y alcanzar la circulación sistémica. Dentro de los efectos que pueden tener en el organismo, los péptidos bioactivos podrían alterar el metabolismo celular y actuar como vasorreguladores, factores de crecimiento, inductores hormonales y neurotransmisores ${ }^{(16)}$.

La proteína sérica predominante en la leche humana es la $\alpha$-lactoalbúmina, siendo su concentración en la leche madura (a partir del día 30) de unos $2.44 \mathrm{~g} / \mathrm{L}{ }^{(23)}$. Es una subunidad reguladora (subunidad B) de la enzima lactosa sintetasa, que en el organismo materno es una enzima crítica para el control de la lactación y la secreción de leche ${ }^{(24)}$. A 
parte de ser una buena fuente de aminoácidos esenciales como el triptófano y la cisteina, presenta actividad prebiótica sobre Bifidobacterium ${ }^{(25)} \mathrm{y}$, una vez que se digiere a nivel intestinal libera péptidos con actividad antimicrobiana ${ }^{(26)}$, inmunomoduladora ${ }^{(16)}$ y opiode (24).

De entre todos los péptidos presentes en la leche materna destacan aquellos con actividad opiácea, que ejercen su acción sobre el sistema digestivo (Tabla 1).

Tabla 1. Ejemplos de péptidos bioactivos procedentes de las proteínas de la leche

\begin{tabular}{llll} 
Proteína precursora & Fragmento & Nombre & Referencia \\
\hline $\boldsymbol{\beta}$-caseína & $60-70$ & $\beta$-casomorfina-11 & Meisel, 1986 \\
& $60-66$ & $\beta$-casomorfina-7 & Kayser et al., 1996 \\
& $60-64$ & $\beta$-casomorfina-5 & Henschen et al., 1979 \\
\hline $\boldsymbol{\alpha}_{\text {s1-caseína }}$ & $90-96$ & $\alpha$-caseína exorfina & Loukas et al., 1983 \\
& $90-95$ & $\alpha$-caseína exorfina & Loukas et al., 1983 \\
& $91-96$ & $\alpha$-caseína exorfina & Loukas et al., 1983 \\
\hline $\boldsymbol{\kappa}$-caseína & $33-39$ & casoxina & Chiba et al., 1989 \\
& $25-34$ & casoxina c & Chiba et al., 1989 \\
\hline $\boldsymbol{\alpha}$-lactoalbúmina & $50-53$ & $\alpha$-lactorfina & Mullally et al., 1996 \\
\hline $\boldsymbol{\beta}$-lactoglobulina & $102-105$ & $\beta$-lactorfina & Antila et al., 1991 \\
\hline albúmina sérica & $399-404$ & serorfina & Tani et al., 1994 \\
\hline
\end{tabular}

Estos péptidos tienen en común una carga negativa en el grupo fenólico del residuo de tirosina y la presencia de otro aminoácido aromático en la tercera o cuarta posición, lo que va a favorecer la fijación del péptido al receptor opiáceo ${ }^{(35)}$.

Estos péptidos se unen a sus receptores en el lumen intestinal, ejerciendo un efecto local sin necesidad de absorción sistémica, reduciendo el reflejo peristáltico mediante reducción de la respuesta refleja; de manera que actúan como moduladores exógenos de la motilidad gastrointestinal, de la permeabilidad intestinal y de la liberación de hormonas intestinales. Así, se ha visto que las $\beta$-casomorfinas, procedentes de la caseína, son capaces de reducir la secreción gástrica y la motilidad intestinal, lo que va a favorecer la digestión del lactante. Además, este tipo de actividad ha despertado un gran interés por su posible papel beneficioso en el tratamiento de la diarrea ${ }^{(16,36)}$.

Por otro lado, debido a la mayor permeabilidad de la mucosa intestinal del lactante, estos péptidos podrían alcanzar la circulación sistémica y llegar al cerebro donde van a afectar al comportamiento emocional, van a producir un efecto sedante y van a regular la ingesta ${ }^{(37)}$. Estos efectos se ven reforzados con la presencia, en la leche materna, de neuropéptidos, entre los que destacan: la neurotensina, la sustancia $\mathrm{P}$, la somatostatina y el péptido vasoactivo ${ }^{(13)}$.

Otros péptidos biactivos procedentes de las proteínas de la leche presentan actividad antitrombótica (como la casoplatelina procedente de la $\kappa$-caseína), antihipertensiva (como la $\alpha$-lactorfina procedente de la lactoalbúmina o las casoquininas procedentes de las caseínas) e inmunomoduladora (como la $\beta$-casokinina-10 o los péptidos procedentes de la 
fermentación de la $\beta$-caseína por bacterias del ácido láctico), incrementan la absorción de minerales (los caseinofosfopéptidos) y modulan la secreción de insulina ${ }^{(16,37,38)}$.

Prácticamente todas las proteínas mayoritarias de la leche materna son capaces de liberar péptidos bioactivos tras la digestión gastrointestinal. Por ejemplo, la lactoferrina es capaz de liberar dos péptidos con actividad biológica: la lactoferricina y la lactoferroxina que tienen actividad antimicrobiana y opiode respectivamente ${ }^{(13,20)}$.

\section{Aminoácidos}

Hay que tener en cuenta que la leche materna aporta los aminoácidos esenciales requeridos por los lactantes en la proporción adecuada. Es importante también considerar la presencia de otros aminoácidos libres, que no forman parte de las proteínas como la carnitina, que participa en los procesos de translocación de la membrana celular, facilitando activamente el paso de ácidos carboxílicos que han sido activados a nivel del coenzima $A$ a través de la membrana mitocondrial, liberando sustratos para oxidación y eliminando compuestos tóxicos (39)

En niños, la producción inmadura por parte del hígado de $\gamma$-butirobetaína hidroxilasa, enzima que participa en la ruta biosintética de la carnitina, incrementa la importancia del suplemento exógeno de este aminoácido, ya que su déficit puede dar lugar a trastornos del metabolismo lipídico y disminución de la cetogénesis ${ }^{(39)}$.

La carnitina participa en una larga lista de procesos metabólicos como:

1. control del aumento de carbohidratos sintetizados por el organismo a partir de las proteínas

2. metabolismo proteico, participando en la inhibición de la proteolisis muscular, en estrecha relación con el metabolismo de los aminoácidos de cadena ramificada ${ }^{(40)}$

3. disminución del colesterol y los triglicéridos del plasma ${ }^{(41)}$

4. contractibilidad miocárdica ${ }^{(42)}$ y

5. parece influir en el desarrollo y maduración de las estructuras cerebrales ${ }^{(42)}$

En los lactantes, las concentraciones plasmáticas de carnitina sufren un marcado descenso poco después del nacimiento ${ }^{(43)}$, por lo que la ESPGHAN recomienda desde 1991 que las fórmulas para recién nacidos de bajo peso contengan L-carnitina en concentraciones al menos similares a las de la leche materna ${ }^{(44)}$.

Otro aminoácido importante es la taurina, que es el aminoácido libre más abundante en el cerebro humano durante el período fetal y los primeros meses de vida ${ }^{(45)}$. Debido a su capacidad osmorreguladora, se considera que las elevadas concentraciones de taurina en el cerebro, como las observadas en lactantes alimentados con leche materna, podrían proteger al sistema nervioso de los efectos adversos debidos tanto a la hipo como a la hiperosmolaridad $^{(46)}$.

Se ha demostrado que en el recién nacido la actividad hepática de ciertas enzimas que participan en el metabolismo de taurina es escasa, por lo que es imprescindible un aporte exógeno de este aminoácido. Dado que en la leche de vaca, a diferencia de la leche materna, las concentraciones de taurina son prácticamente nulas, en los lactantes alimentados con leches infantiles es necesaria la suplementación con este aminoácido para evitar situaciones carenciales ${ }^{(43)}$. 


\section{Nucleótidos}

Los nucleótidos y sus metabolitos derivados desempeñan un papel clave en numerosos procesos bioquímicos y fisiológicos, tales como procesos de transferencia de energía, son precursores de la síntesis de ácidos nucleicos y son claves en la síntesis de carbohidratos, lípidos y proteínas ${ }^{(13)}$.

Los nucleótidos pueden ser sintetizados endógenamente, sin embargo pueden llegar a ser insuficientes cuando esta síntesis no es capaz de cubrir las necesidades del organismo, tal como sucede en ${ }^{(43)}$ :

1. la prematuridad

2. en el retraso del crecimiento fetal

3. en afecciones intestinales y

4. en situaciones de ingesta de nutrientes limitada

La leche materna contiene, en forma libre, ribonucleótidos y ribonucleósidos, los cuales representan del 2 al $5 \%$ del nitrógeno no proteico de la leche materna (Tabla 2). La cantidad nada despreciable presente en la leche humana podría contribuir a la excelente utilización de la proteína por los niños alimentados con leche materna ${ }^{(13)}$. Además, la leche materna contiene cantidades significativas de compuestos relacionados: nucleósidos, bases púricas y pirimidínicas, ácidos nucleicos y productos que se derivan de ellos (como la uridina difosfato galactosa) ${ }^{(47)}$.

Tabla 2. Contenido en ribonucleótidos y ribonucleósidos en la leche humana madura (mg/L) (Gil y Sánchez-Medina, 1982; Topp y col., 1993; Leach y col., 1995;

Schlimme and Schneehagen, 1995)

\begin{tabular}{lccccc} 
& Adenina & Citosina & Guanina & Uracilo & Total \\
\hline \hline Ribonucleótidos & 7,8 & 7,0 & 1,2 & 4,8 & \\
\hline Ribonucleósidos & $0,4-1,8$ & $1,2-1,0$ & $0,1-0,3$ & $0,1-0,7$ & \\
\hline $\begin{array}{l}\text { Nucleótidos totales } \\
\text { parcialmente disponibles }\end{array}$ & 10,6 & 29,3 & 6 & 12,6 & $67,2-67,5$ \\
\hline
\end{tabular}

Los principales efectos de los nucleótidos son:

- modulan la respuesta inmune tanto a nivel humoral como celular $(52,53)$

- favorecen la renovación del epitelio intestinal ${ }^{(47)}$, reducen la duración de la diarrea ${ }^{(54)}$, disminuyen el estreñimiento, meteorismo y regurgitaciones ${ }^{(55)}$ y tienen un efecto beneficioso sobre la flora fecal ${ }^{(56)}$

- modulan el crecimiento hepático y su regeneración ${ }^{(57)}$

- incrementan las concentraciones plasmáticas y eritrocitarias de ácidos grasos poliinsaturados de cadena larga que van a favorecer la elongación de los ácidos grasos esenciales e impiden la inhibición de las desaturasas ${ }^{(13)}$

La leche humana tiene una alta concentración de ribonucleótidos, mientras que en la leche de vaca, con la que se elaboran la mayoría de las fórmulas infantiles, se encuentran prácticamente ausentes ${ }^{(43)}$. Este hecho justifica la necesidad de aportar nucleótidos como complemento a las fórmulas infantiles para favorecer el normal desarrollo de los lactantes. 
Debido a esto, la legislación permite la adición a las fórmulas para lactantes y a las leches de continuación, nucleótidos en cantidades de: 1,5 mg de adenosina-5-fosfato/100 kcal, 2,5 $\mathrm{mg}$ de citosina-5-fosfato/100 kcal, $0,5 \mathrm{mg}$ guanosina-5-fosfato/100 kcal, 1,75 mg uridina-5fosfato/100 kcal, $1,00 \mathrm{mg}$ inopina-5-fosfato/100 kcal; hasta una concentración total de 5 $\mathrm{mg} / 100 \mathrm{kcal}$, lo cual es similar a las cantidades de ribonucleótidos libres en la leche materna (entre 4-6 mg/100 kcal) ${ }^{(58)}$.

\section{Hormonas y factores de crecimiento}

Estos compuestos tienen, de forma general, escasa influencia en el adulto debido a la poca permeabilidad del epitelio intestinal. Ahora bien, es importante destacar que en pacientes con afecciones intestinales, la mayor permeabilidad intestinal asociada a estas patologías podría permitir actuar a estos compuestos. Lo mismo pasa en recién nacidos (donde al igual que en el caso de los péptidos bioactivos, además es mayor la resistencia de estas hormonas a la acción proteolítica) ${ }^{(13)}$.

Dentro del grupo de hormonas presentes en la leche humana se incluyen: isómeros de la prolactina, leptina, estradiol, oxitocina, hormona adenocorticotropa, hormona estimulante del tiroides, hormona del crecimiento, tiroxina, cortisol e insulina. Es importante destacar que las concentraciones de algunas hormonas en la leche humana como es el caso de la insulina exceden a aquellas encontradas en suero $(7,59)$. En general, se ha observado que la concentración de hormonas en la leche materna va disminuyendo durante el tiempo de lactación ${ }^{(59)}$.

Así, por ejemplo, en el lactante, la prolactina podría influir en la función adrenal y gonadal, y estimular el apetito ${ }^{(60)}$. La leptina participaría en la regulación del gasto energético, el apetito y el metabolismo ${ }^{(59)}$. La oxitocina podría regular la función renal por su similitud con la vasopresina, aunque bajo determinadas circunstancias podría actuar como antagonista de ésta, y actuar como neurotransmisor a nivel cerebral ${ }^{(61)}$.

Dentro de los factores de crecimiento se incluyen el factor de crecimiento epidérmico (EGF), el factor de crecimiento similar a insulina tipo I (IGF-I) y las poliaminas ${ }^{(13)}$. Además, podrían ser considerados factores de crecimiento la lactoferrina y ciertos péptidos, como ya hemos mencionado.

\section{Poliaminas}

La presencia de poliaminas (putrescina, espermidina y espermina) en la leche materna y su importancia en las fórmulas infantiles es conocida desde finales del siglo pasado. Varios autores han cuantificado el contenido de estos compuestos en la leche materna (Tabla 3).

Está demostrado que las poliaminas son factores de maduración para el intestino delgado y desempeñan funciones relacionadas con la diferenciación celular y la proliferación.

Tabla 3. Concentración de poliaminas en leche humana (nmol/dL)

\begin{tabular}{cccc} 
Putrescina & Espermidina & Espermina & \\
\hline \hline $0-61$ & $73-351$ & $72-445$ & Pollack et al., 1992 \\
\hline $108-150$ & $602-820$ & $527-799$ & Romain et al., 1992 \\
\hline $20-28$ & $200-240$ & $297-329$ & Buts et al., 1995 \\
\hline
\end{tabular}


Forman parte de la alimentación normal del lactante, siendo secretados por la glándula mamaria. Los factores que van a modifican la cantidad de poliaminas en la leche humana son: genéticos, la fase de lactancia, factores ambientales, el estado nutricional y la dieta ingerida ${ }^{(13,65)}$.

La acción de las poliaminas sobre el crecimiento, desarrollo y la permeabilidad intestinal no es del todo conocida y suscita controversia. Al parecer pueden ejercer efectos tróficos directos sobre las células intestinales inmaduras, mejorando la permeabilidad de la mucosa, afectando también a la maduración de órganos asociados como hígado y páncreas; y obteniéndose paralelamente una maduración del sistema inmune intestinal, afectando particularmente a la diferenciación de la población linfocitaria intraepitelial ${ }^{(13,66)}$. Además, la espermina de la dieta podría afectar al sistema endocrino y nervioso gastrointestinal, modulando la liberación de corticosterona y ácido $\gamma$-aminobutírico ${ }^{(66)}$.

Se ha visto que en ratas lactantes producen un incremento de todos los parámetros de crecimiento de la mucosa, inducen prematuramente un patrón adulto de las enzimas de la mucosa (lactasa, sacarasa, maltasa y aminopeptidasa) e incrementan la concentración de inmunoglobulinas en las vellosidades y en las criptas ${ }^{(67)}$.

Por otro lado se ha demostrado que la ingesta insuficiente de poliaminas induce sensibilización a los alérgenos de la dieta. La probabilidad de desarrollar una alergia puede alcanzar el $80 \%$ si el contenido medio de espermina es inferior a $0,4 \mathrm{mg} / \mathrm{L}$ y prácticamente no existe si el contenido medio de espermina supera los $2,6 \mathrm{mg} / \mathrm{L}$. La espermina incrementa la proliferación y la diferenciación de linfocitos aislados de niños ${ }^{(68)}$.

Diversos estudios demuestran que la administración oral de espermina y espermidina en ratas prematuras aumenta la maduración intestinal, con cambios en la expresión enzimática y en los componentes secretados (como la $\lg A$ ). El efecto es dependiente de la dosis y específico (ya que la administración de ornitina y arginina, que son precursores de la síntesis de poliaminas, no tiene el mismo efecto). El problema es que en estos estudios la dosis administrada era mucho mayor que la que las ratas ingieren por la leche materna. Aun así, asumiendo que los recién nacidos consumen unos $600-700 \mathrm{ml}$ de leche al día (unos 3,5 $\mu \mathrm{mol}$ de poliaminas), el contenido en poliaminas podría, teóricamente, tener un efecto bioactivo ${ }^{(64)}$. También se ha visto que la espermidina y la espermina presentes en la leche materna disminuyen la permeabilidad intestinal a macromoléculas y quizás sea este el mecanismo por el que reducen la frecuencia de alergias alimentarias en niños ${ }^{(67)}$.

Hay que tener en cuenta que la leche de vaca y los productos lácteos tienen bajos contenidos en poliaminas si se compara con la leche humana debido, en parte, a la alta tasa de degradación de poliaminas asociada a una alta actividad de enzimas como la diamino oxidasa y poliamino oxidasa presentes en la leche ${ }^{(65)}$. Esto incluye a las fórmulas artificiales en polvo para la alimentación infantil, donde la concentración de poliaminas es alrededor de 10 veces más baja que en la leche humana ${ }^{(67)}$, por lo que sería muy importante tener estos datos en cuenta a la hora de elaborar dichas fórmulas y asegurar una correcta alimentación durante la etapa de lactancia.

\section{Agentes antiinflamatorios e inmunomoduladores}

Ya hemos comentado que componentes de la leche materna como las proteínas, los nucleótidos o las poliaminas, a pesar de ejercer otras funciones en el bebé lactante, estimulan el desarrollo del sistema inmune. Además, algunos de estos compuestos podrían 
tener una función antiinflamatoria, como por ejemplo las poliaminas, que disminuyen la función antígeno-1 leucocitaria con lo que disminuyen la respuesta inflamatoria ${ }^{(69)}$.

La leche materna contiene otros elementos antiinflamatorios como los antioxidantes, representados por las vitaminas A, C y E, y enzimas como la catalasa, la glutatión peroxidasa y la acetilhidrolasa. También existen antienzimas como la $\alpha_{1}$-antitripsina y la $\alpha_{1}$ antiquimotripsina, que inhiben a las proteasas inflamatorias, y otros compuestos como las postraglandinas, los factores de crecimiento y las citoquinas ${ }^{(70)}$.

\section{CONCLUSIONES}

El conocimiento acerca de los compuestos funcionales presentes en la leche materna y el efecto que tienen en el organismo inmaduro del lactante, va a permitir elaborar fórmulas infantiles cuya composición sea similar a la leche materna. A día de hoy, a pesar de haber conseguido que la calidad nutricional de las fórmulas de inicio sea similar a la de la leche materna, estamos lejos de imitar el aspecto funcional de esta última en cuanto al contenido en compuestos bioactivos. Muchos de estos se encuentran ausentes en la leche de vaca a partir de la cual se elaboran dichas fórmulas, por lo que es importante estudiarlos y conocerlos a fondo con el fin de poder utilizarlos como ingredientes en la elaboración de estos productos. Esto afecta especialmente a las proteínas, ya que el contenido en las diferentes proteínas lácteas difiere entre la leche de vaca y leche humana, lo que va a condicionar la liberación de péptidos bioactivos. Algo similar ocurre en el caso de las poliaminas, donde hay mucha diferencia en los niveles presentes en la leche materna y los encontrados en las fórmulas para lactantes.

Estudios adicionales a los ya realizados que avalasen la necesidad de estos compuestos para el correcto desarrollo de los bebés lactantes, y los estudios que demostrasen fielmente su seguridad toxicológica, justificarían la adición de estos compuestos como ingrediente a las fórmulas de inicio.

\section{Agradecimientos}

A la Fundación Séneca, Agencia Regional de Ciencia y Tecnología, por la beca concedida a Carlos Gómez Gallego para la realización de su tesis doctoral, dentro del programa de Becas-contrato Predoctorales de Formación del Personal Investigador.

Al Ministerio de Ciencia e Innovación por su financiación al proyecto "Nuevos ingredientes de alimentos funcionales para mejorar la salud" (FUN-C-FOOD), Ref. CSD2007-00063.

\section{BIBLIOGRAFÍA}

1. Bosscher, D. and Deelstra, H. Recent advances in the development of infant formulas: mimicking the effects of breast feeding. 2002. Nutrition 18(6): 522-523.

2. Codex Alimentarius Texto abreviado. 1989. Programa conjunto FAO/OMS sobre normas alimentarias. Ed. Smith, B. L. Roma, Italia.

3. Real Decreto $867 / 2008$, de 23 de mayo, por el que se aprueba la reglamentación técnicosanitaria específica de los preparados para lactantes y de los preparados de continuación. BOE num. 131.

4. Kitts, D. D. Bioactive subsances in food: indentification and potential uses.1994. Can J Physiol Pharmacol 72: 423-424. 
5. Kris-Etherton, P. M., Hecker, K. D., Bonanome, A., Coval, S. M., Binkoski, A. E., Hilpert, K. F., Griel, A. E. and Etherton, T. D. Bioactive compounds in foods: their role in the prevention of cardiovascular disease and cancer. 2002. Am J Med. 113: 71-88.

6. Lucas, A. and Cole, T. J. Breast milk and neonatal necrotising enterocolitis. 1990. Lancet 336: 1519-1525.

7. Goldman, A. S. Modulation of the gastrointestinal tract of infants by human milk. Interfaces and interactions. An evolutionary perspective. 2000. J Nut 130: 426S-431S.

8. Greco, L., Auricchio, S., Mayer, M., and Grimaldi, M. Case control study on nutritional risks in celiac disease. 1998. J Paediatr Gastroenterol Nutr 7: 395-399.

9. Norris, J. M. and Scott, F.W. A meta-analysis of infant diet and insulin-dependent diabetes mellitus: do biases play a role? 1996. Epidemiology 7: 87-92.

10. Rigas, A., Rigas, B., Glassman, M., Yen, Y. Y., Lan, S., Petridou, E., Hsieh, C. C. and Trichopoulos, D. Breast-feeding and maternal smoking in the etiology of Crohn's disease and ulcerative colitis in childhood. 1993. Ann Epidemiol. 3: 387-392

11. Mason, T., Rabinovich, C. E., Fredrichson, D. D., Amoroso, K. Reed, A. M., Stein, L. D. and Kredich, D. W. Breast feeding and the developmen of juvenile rheumatoid arthritis. 1995. J Rheumatol. 22: 1166-1170.

12. Davis, M. K., Savitz, D. A. and Grauford, B. Infant feeding in childhood cancer. 1988. Lancet 2: 365-368.

13. Baró, L., Jiménez, J., Martínez-Férez, A. and Boza, J. J. Bioactive compounds derived from human milk. 2001. Ars Pharmaceutica. 42(1): 21-38.

14. Korhonen, H., Pihlanto-Leppälä, A., Rantamäki, P. and Tupasela, T. The functional and biological properties of whey proteins: prospects for the development of functional foods. 1998. Agric Food Sci Finland. 7: 283-296.

15. Wong, C. W. and Watson, D. L. Immunomodulatory effects of dietary whey proteins in mice. 1995. J Dairy Res. 62: 359-368.

16. Baró, L., Jiménez, J., Martínez-Férez, A. and Boza, J. J. Bioactive milk péptidos and proteins. 2001. Ars Pharmaceutica. 42(3-4): 135-145.

17. Jayashree, S., Bhan, M. K., Kumar, R., Bhandari, N. and Sazawal, S. Protection against neonatal rotavirus infection by breast milk antibodies and trypsin inhibitors. 1988. J Med Virol. 26(3): 333-338.

18. Zhang van Bree, S. van Rood, J. J. and Claas, F. H. J. Influence of breast feeding on the cytotoxic T cell allorepertoire in man. 1991. Transplantation. 52: 914-916.

19. Lawrence, R. A. Lactancia Materna. 2007. 6a ed. Elsevier España. ISBN 8481749850 , 9788481748854. p192.

20.Korhonen, H., Pihlanto-Leppälä, A., Rantamäki, P. and Tupasela, T. Impact of processing on bioactive proteins and peptides. 1998. Trends Food Sci Technol. 9: 307-319.

21. Rodríguez-Franco, A., Vazquez-Moreno, L. y Ramos-Clamont, G. Actividad antimicrobiana de la lactoferrina: mecanismo y aplicaciones clínicas potenciales. 2005. Rev Latinam Microbiol. 47 (3-4): 102-111.

22. Ward, P. P., Uribe-Luna, S. and Conneely, O. Lactoferrin and host defense. 2002. Biochem Cell Biol. 80: 95-102.

23. Jackson, J. G., Janszen, D. B., Lönnerdal, B., Lien, E. L., Pramuk, K. P. and Kuhlman, C. F. A multinational study of $\alpha$-lactalbumin concentrations in human milk. 2004. J Nutr Biochem. 15 (9): 517-521

24. Chatterton, D., Smithers, G., Roupas, P. and Brodkorb, A. Bioactivity of $\beta$-lactoglobulin and $\alpha$-lactalbumin-Technological implications for processing. 2006. Int Dairy J. 16: 1229-1240.

25. Maase, K. and Stejins, J. M. Use of $\alpha$-lactalbumin as prebiotic agent. 2002. Campina Melkunie BV (The Netherlands) Patent number: WO 02/060279. 
26. Pellegrini, A., Dettling, C., Thomas, U. and Hunziker, P. Isolation and identification of three bactericidal domains in the bovine $\alpha$-lactalbumin molecule. 1999. Biochim. Biophys. Acta. 1426 (3), 439-448.

27. Meisel, $\mathrm{H}$. Chemical characterization and opioid activity of an exorphin isolated from in vivo digests of casein. 1986. FEBS Letters. 196(2):223-227.

28. Kayser, $\mathrm{H}$. and Meisel, $\mathrm{H}$. Stimulation of human peripheral lymphocytes by bioactive peptides derived from bovine milk proteins.1996. FEBS Letters, 383: 18-20.

29. Henschen A., Lottspeich F., Brantl V., Teschemacher H. Novel opiod peptides derived from casein ( $\beta$-casomorphins). II. Structure of active components from bovine casein peptone. 1979. Hoppe-Seylers Z Physiol Chem 360, 1217-1224.

30. Loukas, S., Varoucha, D., Zioudrou, C., Streaty, R. and Klee, W.A. Opioid activities and structures of a-casein derived exorphins. 1983. Biochemistry 22: 4567-4573.

31. Chiba, H. and Yoshikawa, M. Biologically functional peptides from food proteins: New opioid peptides from milk proteins.1986. Protein Tailoring for Food and Medical Uses, eds., R.E. Feeney and J.R. Whitaker, New York, Marcel Dekker pp. 123-153.

32. Mullally, M.M., Meisel, H. and FitzGerald, R.J. Synthetic peptides corresponding to alactalbumin and b-lactoglobulin sequences with angiotensin-I-converting enzyme inhibitory activity. 1996. Biol. Chem. Hoppe-Seyler 377: 259-260.

33. Antila, P., Paakkari, I., Järvinen, A., Mattila, M.J., Laukka-nen, M., Pihlanto-Leppälä, A., Mäntsälä, P.and Hellman, J. Opioid peptides derived from in vitro proteolysis of bovine whey proteins.1991. Int. Dairy J. 1:215-229.

34. Tani, F., Shiota, A., Chiba, H. and Yoshikawa, M. (1994). Serorphin, an opiod peptide derived from bovine serum albumin. Casomorphins and related peptides: Recent developmets, eds., V. Brantl and H. Teschemcaher, Weinheim, VCH-Verlag, pp. 4953.

35. Hernández-Ledesma, B. Caracterización y bioactividad de péptidos obtenidos a partir de proteínas lácteas mediante hidrólisis enzimática y procesos fermentativos. 2002. Tesis doctoral. Universidad Complutense de Madrid. ISBN: 84-669-2033-1.

36. Allescher, H. D., Storr, M., Piller, C., Brantl, V. and Schusdziarra, V. Effect of opioide active therapeutics on the ascending reflex pathway in the rat ileum. 2000. Neuropeptides. 34: 181-186.

37. Pihlanto-Leppälä, A., Antila, P., Paakkari, I. and Korhonen, H. Biologically Active Peptides Derived from Milk Proteins. Web-Compilations on Food System Functionality: volume I. www. msstate.edu/org/fsfa/vol1. Copyright 2002 Food System Functionality USA. Starkville, MS http://www.msstate.edu/org/fsfa/vol1.htm

38. Jolles, P., Levy-Toledano, S., Fiat, A. M., Soria, P., Gillesen, D., Thomaidis, A., Dunn, F. W., Caen, J. P. Analogy between fibrinogen and casein. Effect on an undecapeptide isolated from $\kappa$-casein on platelet function. 1986. Eur J Biochem.158: 379-382.

39. Pérez-Conesa, D. Calidad de la proteína en las distintas fases de procesado de las harinas de cereales infantiles. 1998. Tesis de Licenciatura. Universidad de Murcia.

40. Campoy, C., Pedrosa, T., Rivero, M. and Bayes, R. Papel de la carnitina en la inhibición de la proteolisis muscular en el periodo neonatal. 1994. XXI Reunión Anual de la Asociación Española de Pediatría. Barcelona, 1-4 junio 1994.

41. Daynandan, A., Kumar, P., Kaalaiselvit, T and Panneerselvam, C. Effects of Lcarnitine on blood lipid composition in atherosclerotic rats. 1994. J Clin Biochem Nutr. 17: 81-87.

42. Bresilin, N., Freddo, L. and Vergani, L. Carnitine acyltransferase and rat brain function. 1982. Exp Neurol. 78: 285-292. 
43. Rivero Urgell, M., Santamaría Orleans, A. and Rodríguez-Palmero Seuma, M. La importancia de los ingredientes funcionales en las leches y cereales infantiles. 2005. Nutr Hosp. 20 (2): 135-146.

44. ESPGHAN. Comité on Nutrition. Comment on the content and composition of lipids in infant formulas. 1991. Acta Paediatr Scand. 80: 887-896.

45. Sturman, J. A. and Chesney, R. W. Taurine in pediatric nutrition. 1995. Ped Clin North Am. 42 (4): 879-897.

46. Sturman, J. A. Taurine in development. 1988. J Nutr. 118: 169-176.

47. Gil, A. and Uauy, R. Nucleótides and related compounds in human and bovine milks. 1995. In: Jensen, R. G. ed. Handbook in milk composition, Academic Press, New York. 436-464.

48. Gil, A. and Sánchez-Medina, F. Acid-soluble nucleotides of human milk at different stages of lactation. 1982. J Dairy Res. 49: 301-307.

49. Topp, H., Duden, R. and Schoch, G. 5-6-Dihydrouridine: a marker ribonucleoside for determining whole body degradation rates of transfer RNA in man and rats.1993. Clin Chim Acta. 17: 73-82.

50. Leach, J. L., Baxter, J.H., Molitor, B. E., Ramstack, M. B., Masor, M. L. Total potentially available nucleotides of human milk by stage of lactation. 1995. Am J Clin Nutr. 61: 1224-1230.

51. Schlimme, E. and Schneehagen, K. Ribonucleosides in human milk. Concentration profiles of these minor constituents as a function of nursing time.1995. Z Naturforsch 50: 105-113.

52. Carver J. D., Pimentel, B., Cox, W. I. and Barness, L. A. Dietary nucleotide effects upon immune function in infants. 1991. Pediatrics. 88: 359-363

53. Carver J. D. Dietary nucleotides: cellular immune, intestinal and hepatic system effects. 1994. J Nutr. 124: 144S-148S.

54. Lama, R. A., Gil-Alberdi, B. Efecto de la suplementación dietética con nucleótidos sobre la diarrea en el lactante sano. 1998. An Esp Pediatr. 48: 371-375.

55. Alvaro, G. Evaluation of the effect of a new milk formula with added nucleotides on some gastrointestinal functions. Results of a nation-wide study of 5009 infants. 1998. Pediatric Study grup. Minerva Pediatr. 50: 347-358.

56. Gil, A. Corral, E., Martínez, A. and Molina, J. A. Effects of the addition of nucleotides to an adapted milk formula on the microbial pattern of faeces in at term newborn infants. J Clin Gastroenterol Nutr. 1986, 1: 127-132.

57. Carver J. D. Nucleótidos. 1996. Anales Nestlé. 54: 99-109.

58. Report of the Scientific Committee on Food on the Revision of Essential Requirements of Infant Formulae and Follow-on Formulae, 2003. European Commission.

59. Ozarda, Y., Banu, Z. and Ozkan, T. Leptin concentration in breast milk and its relationship to duration of lactation and hormonal status. 2006. International Breastfeeding Journal, 1:21.

60. Woodside, B. Prolactin and the hyperphagia of lactation. 2007. Physiol Behav. 24; 91(4):375-82.

61. Kosfeld, M., Heinrichs, M., Zak, P. J., Fischbacher, U. and Fehr, E. Oxytocin increases trust in humans. 2005. Nature 435:673-676

62. Pollack, P.F., Koldovsky, O. and Nishioka, K. Polyamines in human and rat milk and in infant formulas. 1992. Am J Clin Nutr. 56:371-375.

63. Romain, D., Dandrifosse, G., Jeuselte, Forget, G. Polyamine concentration in rat milk and food, human milk and infant formulas. 1992. Pediatr Res. 31: 73-80.

64.Buts, J.P., Dekeyser, N., Deraedemaeker, L., Collete, E., Sokal, E.M. Polyamine profiles in human-milk, infant artificial formulas, and semielemental diets. 1995. J Ped Gast Nut. 21 (1): 44-49. 
65. Löser, C. Polyamines in human and animal milk. 2000. Br J Nut. 84 (Suppl.1): S55S58.

66. Dandrifosse, G., Peulen, O., El Khefif, N., Deloyer, P., Dandrifosse, A. C., Grandfils, C. Are milk poliamines preventive agents against food allergy? 2000. Acta Pediatr Scand. 76:733-740.

67. Motyl, T., Ptoszaj, T., Wojtasik, A., Kukulska, W. and Podgurniak M. Polyamines in cow's and sow's milk. 1995. Comp Biochem Physiol. 111 B, 427-433.

68. Kalac, P. and Krausova, P. A review of dietary polyamines: Formation, implications for growth and health and occurrence in foods. 2005. Food Chemistry. 90: 219-230.

69. Soda, K. Polyamines. 2003. Food Science Journal. 11, 40-49

70. Aguilar, M.J. Lactancia Materna. 2005. Ed. Elsewier. ISBN 8481747688, 9788481747683. 254. 